\title{
AI, Automation and New Jobs
}

\author{
Jaures Badet \\ Department of Economics, Necmettin Erbakan University, Konya, Turkey \\ Email: dulambadet@gmail.com
}

How to cite this paper: Badet, J. (2021). AI, Automation and New Jobs. Open Journal of Business and Management, 9, 2452-2463. https://doi.org/10.4236/ojbm.2021.95132

Received: July 23, 2021

Accepted: September 19, 2021

Published: September 22, 2021

Copyright (c) 2021 by author(s) and Scientific Research Publishing Inc. This work is licensed under the Creative Commons Attribution International License (CC BY 4.0).

http://creativecommons.org/licenses/by/4.0/

\begin{abstract}
Our study analyzes the advantages that automation presents for the job. The main new feature of our framework is that, in addition to the part of jobs that are displaced by automation, it also leads to the creation of new, more complex versions of existing tasks, which leads to the demand for employment. We focused more on the essential factor which is the degree of skill to take advantage of these new jobs. We carry out research based on information relating to automation and jobs. Also, by using the output of the final good model, we show that the creation of new tasks in which the labor has a comparative advantage is one of the positive aspects of automation. We find that automation will create new jobs (smart jobs) and eliminates repetitive jobs which will be replaced by machines in the future. However, these new jobs will need high skills. Therefore, the level and quality of education will play important role in the new jobs that automation will generate. Workers and future students must prepare themselves by focusing their training more on the skills that new technologies will require. Automation may prepare us for a future in which workers with low skills will be forced to change occupations or lose their occupations, which will be completely occupied by machines. We find also that the job loss depends on the speed of automation in each country. Based on the economic structure, the investment policy in new technology, and the level of education of countries, the speed at which automation spread is slower in some countries and intense in others. Therefore, the job is more at risk in countries with high automation than in those with medium or low automation.
\end{abstract}

\section{Keywords}

Automation, AI, New Jobs, Skill

\section{Introduction}

An intense debate has intensified for years around the question of the future of work with the advent of machines. This debate has taken on a little more mo- 
mentum these days especially in the period of the COVID 19 pandemic when the use of technology has become essential to face the health crisis. There are many questions about automation and its impact on work. Are we going to see an era where humans will be sidelined in industries to the detriment of machines? What is the future of employment with machines? What will be the role of automation in industries? What is the place of humans in the automation system? One thing is certain: today production in most industries requires the simultaneous completion of a series of tasks. Some difficult and complex tasks are even beyond human skill and therefore require the assistance of machines. The majority of these tasks are therefore performed either with machines or with a combination of man and machines. The real question is if the tasks will be displaced definitively by machines or not. Most of the debates and works have been centered on the fact that many jobs will be replaced in the industry by machines and in the same way, automation will create the advent of new jobs. For example, according to Manyika and Sneader (2018), around 15 percent of the global workforce, or around 400 million workers, could be displaced by automation during the period 2016-2030. According to the same authors, the demand for labor due to automation until 2030 would be between $21 \%$ and $33 \%$ of the global workforce or 555 million and 890 million jobs. This demand for labor can largely compensate for the number of jobs lost caused by automation. They also support the idea that all occupations can't be affected by automation. Only about 5\% of occupations could be fully automated by technology. About 30 percent of the activities in 60 percent of all professions could be automated. In addition, automation affects less-educated workers and employees in less educated jobs. The displacement of human labor by automation will create a displacement effect and reduce labor demand. But this displacement effect can be counterbalanced by other economic factors like productivity, capital accumulation, the deepening of automation, and the creation of new tasks. Those factors lead to an increase in labor demand. Moreover, automation will lead to the decline in the share of labor in national income, but at the same time by the creation of new tasks, this negative effect will be offset. New tasks increase the demand for labor and tend to raise the labor share (Acemoglu \& Restrepo, 2018). Automation causes jobs to be lost in some industries and jobs to increase in others (Bessen, 2017). According to Zinser et al. (2015), a forecast made by a global consulting group, the share of tasks performed by robots in all manufacturing industries today will increase by 15 percent by 2025 (from a global average of around $10 \%$ to around 25\%). Acemoglu and Restrepo (2016) think that, in a static version where the capital is fixed and technology is exogenous, automation leads to a reduction in employment and the share of labor, but the creation of new tasks generated by this automation causes an increase of labor demand.

Other authors argue that not all jobs can be automated despite the advent of machines. According to Arntz et al. (2016), many workers specialize in tasks that cannot be automated easily, which doesn't put in danger the employment mar- 
ket too much. Other studies point out that automation mainly affects jobs where workers have low skill levels. According to a European survey about skills and employment from Cedefop, "around 14\% of jobs in the EU are at risk of displacement by computer algorithms. The jobs most likely to be affected are those which depend more on routine tasks and which require few transversals and interpersonal skills" (CEDEFOP, n.d.). In addition, automation will affect low-skilled workers more than skilled workers (Arntz et al., 2016). Graetz and Michaels (2015) argue also that the use of robots in industries reduces the employment share of low-skilled workers rather than total employment. The threat of automation on jobs is less and heterogeneous. It varies depending on the economic policy, the level of education, and the investment of each country in new technology. Acemoglu and Restrepo (2017) and Chiacchio et al. (2018) underline the fact that automation affect wages and employment in two ways: The direct displacement of workers from the tasks they previously performed creates displacement effect which negatively affects employment and the increase in demand for labor by industries which creates productivity effect which positively affects wages and employment.

As we saw, many points are often covered in studies about automation and employment. For example, the non-automation of all sectors of industry, the advent of new jobs caused by high automation, the collaboration between robots and humans, and the displacement of certain jobs by machines. The second point, that of the advent of new jobs caused by automation, is discussed more in our study. Our study is therefore more focused on the advantages that automation presents for the job. The dimension of displacement of jobs by automation is not discussed too much in this study. We do so for a reason: The predictions of automation causing massive job losses are not too much in line with reality. According to some reports, automation will even create more jobs than it will displace. Therefore, the main new feature of our framework is that, in addition to the part of jobs that are displaced by automation, it also leads to the creation of new, more complex versions of existing tasks, which leads to the demand for employment. We focused more on the essential factor which is the degree of skill to take advantage of these new jobs.

In this study, Section 2 presents the relevant literature on the impact of AI and automation on jobs. Section 3 focuses on automation and new jobs; especially this section sheds light on the creation of new jobs by automation. In Section 4 the relationship between skills, technologies, and jobs is discussed. In Section 5, how automation leads to the creation of new jobs is shown by using the output of the final good model used by Acemoglu and Restrepo (2016) and Zeira (1998). Finally, in Section 6 a discussion on AI, automation, and new jobs were conducted.

\section{Relevant Literature}

In this section, the relevant literature on the impact of $\mathrm{AI}$ and automation on 
jobs is surveyed. Acemoglu and Restrepo (2017) analyze the effect of the increase in industrial robot usage between 1990 and 2007 on US local labor markets. They show that robots may reduce employment and wages and that the local labor market effects of robots can be estimated by regressing the change in employment and wages on the exposure to robots in each local labor market-defined from the national penetration of robots into each industry and the local distribution of employment across industries. They find that one more robot per thousand workers reduces the employment to population ratio by about $0.18-0.34$ percentage points and wages by $0.25-0.5$ percent. Frey and Osborne (2017) examine the expected impacts of future computerization on labor market outcomes by implementing a novel methodology to estimate the probability of computerization for 702 detailed occupations. They find that around $47 \%$ of total US employment is at high risk in the future. According to them, most occupations such as transportation and logistics, office and administrative support occupations, and jobs in production industries are at risk. Dauth et al. (2017) analyze the impact of rising robot exposure on the careers of individual manufacturing workers, and the equilibrium impact across industries and local labor markets in Germany. They find that robots do not cause total job losses but affect the composition of overall employment. Robots decrease overall employment in Germany by nearly 23 percent in the period 1994-2014. This represents approximately 275.000 jobs. They also find that this loss is fully offset by additional jobs in the service sector. Berriman and Hawksworth (2017) conclude that almost $30 \%$ of jobs in the UK could be automated in the early 2030s. According to them, education will play an important role in this automation process. In the UK, automation affects more jobs requiring a lower level of education (46\%) than those requiring a high level of education. According to the same authors, automation will create new jobs in the field of digitalization. Chiacchio et al. (2018), by studying the impact of industrial robots on employment and wages in six European Union countries, which make up 85.5 percent of the EU industrial robots market, find that robot per thousand workers reduces the employment rate by $0.16-0.20$ percentage points. They also find that the displacement effect is particularly evident for workers of middle education and young cohorts, while men are more affected than women are.

\section{Automation and New Jobs}

The example of Britain with new industries and advent of new jobs as engineers, machinists in 19th century and an America with the mechanization of agriculture at the beginning of 20th century has shown that the intensive automation leads to the emergence of new jobs and news tasks in the industries. The majority of work on automation and job claim that automation will eliminate a lot of jobs but also create a lot of new ones. According to Acemoglu and Restrepo (2018), automation will harm the demand for labor but at the same time, will leads to the creation of new jobs and new tasks. Atkinson and Wu (2017) also 
support the idea that technology not only eliminates jobs but creates them as well. The emergence of technology may eliminate certain professions, leaving room for other more productive professions. Likewise, according to Manyika and Sneader (2018), automation will result in more job creation than job loss (21\% and 33\% of the global workforce, or 555 million and 890 million jobs until 2030). According to Gartner (2017), “AI will create 2.3 million jobs in 2020 while eliminating 1.8 Million", an estimated number that exceeds the number of jobs that are eliminated by the AI in 2020. Chowdhry (2018) also supports the idea that "the growth of artificial intelligence could create 58 million net new jobs in the next few years".

Thus, we can conclude that automation will displace many jobs especially the jobs which require a low level of education and/or skill will be easily automated. However, it will create some new jobs (smart jobs), which require high skills. For example, according to studies, in the future, we will no longer need a taxi driver to move anywhere we want thanks to autonomous cars ${ }^{1}$. The advent of autonomous vehicles in the future is almost inevitable. So what is its impact on taxi drivers? We believe that the advent of autonomous vehicles will generate two situations: The collaboration between taxi drivers and these vehicles and/or the definitive replacement of these jobs by vehicles creating new jobs, which are not identical to the old ones but more complex. Autonomous vehicles can navigate on their own without human intervention but cannot do these kinds of things humans do. For example, drivers repair vehicles or bring them in for repairs when they break down on the way. The job of taxi driving will not go away completely but automation at this level will help taxi drivers do their jobs more easily and better. We may assist in a collaboration between the AI of these cars and the taxi drivers. It is also important to note that automation at this level will require a high degree of skill. Therefore, taxi drivers must requalify their skill level to know how to manage and use these vehicles. Furthermore, if autonomous vehicles replace taxi drivers, it will lead to the creation of other jobs, which may be more complex. Companies will need, for example, engineers, technicians, software developers, and designers to build and manage these autonomous vehicles. These vehicles will break down sometimes and will need humans to repair them. The advent of autonomous vehicles may not benefit taxi drivers if they replace them but will allow other employees with high skills to find work. In any case, the workforce will have an advantage over the machines.

\section{Skill, Technologies and New Jobs}

As it is said in our framework in the previous sections, intensive automation will lead to new tasks and new jobs. But these new jobs need new skills. So the use of efficient machines in industries will require workers who will be able to acquire ${ }^{1}$ The advent of autonomous vehicles will not only have an impact on taxi drivers but many other areas. In this section of our study, we just approached the impact of the advent of autonomous vehicles on taxi drivers. The aim is to show the advantage of this new technology on this job. 
new skills. According to Mckinsey Global Institute (2017), in developing countries, the rate of employment growth is highest for occupations that require a college diploma or higher. In China, for example, there is a high demand for occupations currently requiring university degrees and above. At the same time, nearly 60 million jobs currently require a high school diploma. Moreover, even with the effect of automation, in India, the demand for new employees requiring high school education is nearly 100 million (Mckinsey Global Institute, 2017: p. 85). Automation requires higher skill requirements. The acquisition of more digital skills and the complementarity of key skills are essential in the adaptation of individuals to digital change and automation (CEDEFOP, n.d.). Thus, the industry will need highly qualified professionals whose talents will be in great demand and will be able to train other workers to better master and better adapt to the new tasks that automation will generate. By 2022, 54\% of employees will need to learn new skills to meet the expectations of the new tasks created by automation. Thus $35 \%$ of these workers will need at least training for six months, training for more than 6 years will be necessary for $9 \%$ of workers and $10 \%$ will need training for more than one year (World Economic Forum, 2018). But we often see a mismatch between skills and technologies because workers need to master the use of new technologies in industries but they often do not possess those skills to do those tasks. These new skills often require a high educational or experimental capacity, which workers in most situations do not have. Most of the time it is also difficult for employers to find workers that can master the new jobs and tasks induce by the intensive automation (Deloitte $\&$ the Manufacturing Institute, 2011).

To summarize, jobs displaced by automation require less skill than new jobs generated by the latter. The new jobs require high skills, which will depend on the quality of the educational system of each country. Much of the employment in the future created by automation will require high education levels. In this context, jobs requiring less educational requirements are in danger and at the same time, the demand for jobs requiring educational capacities or higher skills increases. The education system plays a decisive role in the new jobs that will lead to automation. The quality of skill depends on the quality of the educational system. If the educational system is not up to the skill requirements that new jobs require, we often see a mismatch between skills and technologies.

\section{Theoretical Model}

In our model, we analyze the effect of automation and AI on Jobs by considering two type of economy. Firstly, we suggest that in a technologically stagnant economy, all tasks are produced by human. Therefore, jobs are not in danger in this economy. Second, in a technologically advanced economy where most sectors are automated, automation will obviously cause the loss of many jobs. However, these jobs will be more the jobs with repetitive tasks, which do not 
push the workers to raise their level of thinking. At the same time, it will create new, more complex jobs, which will cause workers to think more, to have more creativity in the execution of tasks. In other words, these new jobs will need employees who are able to create new ideas and knowledge useful for the business, think quickly and smartly to solve complex problems, and who have the ability to adapt to the new technology that is in prospect change. Therefore, high skill due to high level and quality of education (only both makes qualified workers) will play an essential role in the "smart jobs" that automation will create. To evince our hypothesis, we use the output of the final good model used by Acemoglu and Restrepo (2016) and Zeira (1998). According to these authors, the output of the final good is given by:

$$
Y=\left(\int_{N-1}^{N} y_{i}^{\frac{\varphi-1}{\varphi}}\right)^{\frac{\varphi}{\varphi-1}}
$$

Final good $Y$ is produced by combining a continuum of tasks $y_{i}$ where $y_{i} \in[N-1 ; N]$ and $\varphi$ denotes the elasticity of substitution between tasks.

By assuming that the range of tasks is between $N-1$ and $N$, the creation of a new task in $N$ corresponds to the replacement of an existing task in $N-1$. The production of each task requires a combination of labor or capital. In industries, not all tasks can be produced by labor. Another task requires the help of machines (capital). Therefore, we have the automated tasks, which are produced by labor with the help of machine, and the non-automated tasks executed only by labor. If there exists $I \in[N-1, N]$ such that

$$
\begin{aligned}
& i \leq I \text { automated tasks } \\
& i>I \text { non autometed tasks }
\end{aligned}
$$

Note that here $i \leq I$ is the automated tasks which are produced by labor or capital as well.

If we assume that the tasks are executed by labor or machine with a specific intermediate task $q(i)$ (the technology used both for production and for the possible automation of tasks), we have:

$$
\begin{aligned}
& y(i)=B\left[\beta q(i)^{\frac{\varphi-1}{\varphi}}+(1-\beta)\left(\gamma_{K}(i) k(i)+\gamma_{L}(i) l(i)\right)^{\frac{\varphi-1}{\varphi}}\right]^{\frac{\varphi}{\varphi-1}} \text { for } i \leq I \\
& y(i)=B\left[\beta q(i)^{\frac{\varphi-1}{\varphi}}+(1-\beta)\left(\gamma_{L}(i) l(i)\right)^{\frac{\varphi-1}{\varphi}}\right]^{\frac{\varphi}{\varphi-1}} \text { for } i>I
\end{aligned}
$$

where $\gamma_{L}(i)$ is the productivity of labor in task $i, \gamma_{K}(i)$ the productivity of capital (machine), $l(i)$ denotes tasks that can be produced by human labor and $k(i)$ the one that will be produced by machine. $\varphi \in(0 ; \infty)$ and represents the elasticity of substitution between intermediates and labor, $\beta \in(0 ; 1)$ represents the distribution parameter of this constant elasticity of substitution production function. B represents a normalizing constant and $B \equiv(1-\beta)^{\frac{\varphi}{1-\phi}}$ to simplify the algebra. 


$$
\begin{aligned}
& y(i)=(1-\beta)^{\frac{\varphi}{1-\phi}}\left[\beta q(i)^{\frac{\varphi-1}{\varphi}}+(1-\beta)\left(\gamma_{K}(i) k(i)+\gamma_{L}(i) l(i)\right)^{\frac{\varphi-1}{\varphi}}\right]^{\frac{\varphi}{\varphi-1}} \text { for } i \leq I \\
& y(i)=(1-\beta)^{\frac{\varphi}{1-\phi}}\left[\beta q(i)^{\frac{\varphi-1}{\varphi}}+(1-\beta)\left(\gamma_{L}(i) l(i)\right)^{\frac{\varphi-1}{\varphi}}\right]^{\frac{\varphi}{\varphi-1}} \text { for } i>I
\end{aligned}
$$

If we assume that $\beta \rightarrow 0$ (the share of revenues going to intermediates is very low $)^{2}$ :

$$
\begin{gathered}
y(i)=1^{\frac{\varphi}{1-\varphi}}\left[\left(\gamma_{K}(i) k(i)+\gamma_{L}(i) l(i)\right)^{\frac{\varphi-1}{\varphi}}\right]^{\frac{\varphi}{\varphi-1}} \text { for } i \leq I \\
y(i)=1^{\frac{\varphi}{1-\varphi}}\left[\left(\gamma_{L}(i) l(i)\right)^{\frac{\varphi-1}{\varphi}}\right]^{\frac{\varphi}{\varphi-1}} \text { for } i>I \\
\forall \varphi \in(0 ; \infty),(1)^{\frac{\varphi}{1-\varphi}}=1 .
\end{gathered}
$$

So:

$$
\begin{aligned}
& y(i)=\gamma_{L}(i) l(i)+\gamma_{K}(i) k(i) \text { for } i \leq I \\
& y(i)=\gamma_{L}(i) l(i) \text { for } i>I
\end{aligned}
$$

Case (a) is currently restricted to a group of countries. This case is more observed in high-income countries and some middle-income countries. Case (b) is more frequent in industries of low-income, and certain middle-income countries. However, this case is also observable in high-income countries because even in these countries not all sectors can be automated.

So, in a technologically stagnant economy, all tasks are produced by labor.

$$
y(i)=\gamma_{L}(i) l(i)
$$

Jobs are not in danger since automation is not evolved in these economies. Even employees with low skills are not exposed to the risk of job loss caused by automation since there is no task produced by machines.

In a technologically advanced economy, tasks are executed totally by human in some sectors and by the humans and machines in others:

$$
\begin{aligned}
& y(i)=\gamma_{L}(i) l(i)+\gamma_{K}(i) k(i) \\
& y(i)=\gamma_{L}(i) l(i)
\end{aligned}
$$

In such an economy, the non-automated sector employees are not exposed to the risk of job loss. In automated sector, an intensive increase in $I$, leads to lower labor costs $(I)$ and the creation of new tasks (more complex) generated by the use of AI and other advanced technologies in automation. The new tasks lead to an increase in the demand for labor. If $\gamma_{L}(i)$ increases strictly in $i$, labor has a comparative advantage in higher-indexed tasks ${ }^{3}$. Even in automated sector, the loss of ancient jobs leads to the creation of new ones that are more complex and ${ }^{2}$ Acemoglu and Restrepo (2016) use the same assumption in their work about "The Race between Man and Machine: Implications of Technology for Growth, Factor Shares and Employment' page 8. ${ }^{3}$ Our theoretical framework builds on Acemoglu and Restrepo (2016) extends Zeira (1998) who develop a model where firms produce intermediates using labor-intensive or capital-intensive technologies. 
will need a high skill. As is discussed in Section 3 of our work, the creation of new tasks in which the labor has a comparative advantage is one of the positive aspects of automation. Even though capital accumulation and deepening automation are important factors in increasing the labor share of national income, the creation of new tasks in which labor has a comparative advantage remains the most important aspect preventing the decline in the share of national income (Acemoglu \& Restrepo, 2018). Therefore, in any case, the workforce will have an advantage over the machines. Furthermore, as we saw in the model, not all sectors can be automated. The speed at which automation spreads depends on the policy and investment in innovation and adoption of technology in each country and each company. For example, the speed of automation in The USA is not the same in most African countries because the goals of innovation and adoption of new technology are not the same in all countries. Therefore, jobs in automated industries are at a higher risk of displacement than those in non-automated or less automated industries. In addition, the quality of education especially higher education will also be important in the process of automation. The companies use advanced technologies like AI and others in automation process. The use of these technologies will need high and qualified skills in digitalization. Therefore, intensive automation will lead to the replacement of low-level jobs and the creation of new jobs that require high skill levels.

\section{Conclusion}

Many questions and debates intensify on the future of jobs with automation especially in the period of COVID-19 where we have seen the importance of new technology in the management of the health crisis. Different authors have different opinions on the future of employment with automation. However, most of the work on this issue supports the fact that automation will replace some jobs in the industry but at the same time create others as well. Our study is focused on the advantages that automation presents for the job. The dimension of displacement of jobs by automation is not discussed too much in this study. We do so for a reason: the predictions of $\mathrm{AI}$ causing massive job losses are not too much in line with reality. According to some reports, automation will even create more jobs than it will displace. Therefore, the main new feature of our framework is that, in addition to the part of jobs that are displaced by automation, it also leads to the creation of new, more complex versions of existing tasks, which leads to the demand for employment. We focused more on the essential factor which is the degree of skill to take advantage of these new jobs.

Firstly, we find that based on the economic structure, the investment policy of countries in new technology, and also the quality of education, the effect of automation on employment varies from country to country. The speed of automation is slower in some countries and very intense in others. Therefore, the job is more at risk in countries with high automation than in those with medium or low automation. In other words, the influence of automation on the job in tech- 
nologically advanced countries is different from that in technologically stagnant countries.

Second, even if machines are more productive than humans are, they cannot do everything in companies. Certain jobs are properly reserved only for human capacity. So not all jobs can be automated in the industry. We may see low demand for labor in the automated sectors but at the same time a strong demand in the non-automated sectors. In addition, jobs with a low skill level are more at risk than those with a high skill level. In another word, jobs consisting of repetitive tasks do not require a high level of education. These jobs are more vulnerable to automation than those that require more thinking and more creativity (High skill). Therefore, in this dynamism of automation, the job of skilled workers is more secure than that of low-skilled workers.

Thirdly, automation will create maybe more jobs than it eliminates in the future. It will replace many jobs especially the jobs with low skill but at the same time as we said in our study, it will create many new jobs, which will need a high skill. Automation is a step forward, an important and necessary revolution for industries in increasing productivity and competitiveness. Not something, that should normally be scary. The key to the jobs that automation will create is high and digital skills. Thus, higher education and training oriented toward digitalization and coding will play a very important role in the new jobs. The future jobs will not be for everybody. To know how to create or manage sophisticated technologies, workers need to get high skills. Therefore, we need to change the way we give or take training. The educative system must be more valued and more oriented to digital skills and coding. Education in the future should be more focused on knowledge of new technologies. Automation is not a threat to us. It is an advantage but to benefit from this automation, workers and future students must prepare themselves by focusing their training more on the skills that new technologies will require. Automation may prepare us for a future in which workers with low skills or simple tasks will be forced to change occupations or lose their occupations, which will be completely occupied by machines. To successfully perform their new tasks, workers will need to acquire the necessary skills. They will therefore need training, so the duration will vary depending on the type of task and the type of skill sought. In any case, automation leaves us many job opportunities. The important thing is to know how to orient the new knowledge to be able to adapt it to the requirements of automation.

\section{Conflicts of Interest}

The author declares no conflicts of interest regarding the publication of this paper.

\section{References}

Acemoglu, D., \& Restrepo, P. (2016). The Race between Man and Machine: Implications of Technology for Growth, Factor Shares and Employment. NBER Working Paper No. 
22252, National Bureau for Economic Research. https://doi.org/10.3386/w22252

Acemoglu, D., \& Restrepo, P. (2017). Robots and Jobs: Evidence from US Labor Markets. NBER Working Paper No. 23285, National Bureau for Economic Research. https://doi.org/10.3386/w23285

Acemoglu, D., \& Restrepo, P. (2018). Artificial Intelligence, Automation and Work. NBER Working Papers No. 24196, National Bureau of Economic Research. https://doi.org/10.3386/w24196

Arntz, M., Gregory, T., \& Zierahn U. (2016). The Risk of Automation for Jobs in OECD Countries. OECD Social Employment and Migration Working Papers, No. 189, Organisation for Economic Co-Operation and Development.

Atkinson, R., \& Wu, J. (2017). False Alarmism: Technological Disruption and the U.S. Labor Market, 1850-2015 (pp. 1-28). Information Technology and Innovation Foundation. https://doi.org/10.2139/ssrn.3066052

Berriman, R., \& Hawksworth, J. (2017). Will Robots Steal our Jobs? The Potential Impact of Automation on the UK and other Major Economies. PwC UK Economic Outlook.

Bessen, J. (2017). Automation and Jobs: When Technology Boost Employment. Law and Economics Research Paper No. 17-09. Boston University School of Law. https://doi.org/10.2139/ssrn.2935003

CEDEFOP (European Centre for the Development of Vocational Training) (n.d.). Automation of Work and Skills.

https://www.cedefop.europa.eu/en/events-and-projects/projects/digitalisation-and-futu re-work/automation-work-and-skills

Chiacchio, F., Petropoulos, G., \& Pichler, D. (2018). The Impact of Industrial Robots on EU Employment and Wages-A Local Labour Market Approach. Working Papers No. 25186. Bruegel.

Chowdhry, A. (2018, September 18). Artificial Intelligence to Create 58 Million New Jobs By 2022, Says Report. Forbes.

https://www.forbes.com/sites/amitchowdhry/2018/09/18/artificial-intelligence-to-creat e-58-million-new-jobs-by-2022-says-report/?sh=1f0b27e24d4b

Dauth, W., Findeisen, S., Südekum, J., \& Wößner, N. (2017). German Robots the Impact of Industrial Robots on Workers. CEPR Discussion Paper No. 12306, Centre for Economic Policy Research.

Deloitte \& The Manufacturing Institute (2011). Boiling Point? The Skills Gap in U.S. Manufacturing. http://www.themanufacturinginstitute.org

Frey, C. B., \& Osborne, M. A. (2017). The Future of Employment: How Susceptible Are Jobs to Computerisation? Technological Forecasting and Social Change, 114, 254-280. https://doi.org/10.1016/j.techfore.2016.08.019

Gartner (2017, December 13). Gartner Says By 2020, Artificial Intelligence Will Create More Jobs than It Eliminates.

https://www.gartner.com/en/newsroom/press-releases/2017-12-13-gartner-says-by-202 $\underline{0 \text {-artificial-intelligence-will-create-more-jobs-than-it-eliminates }}$

Graetz, G., \& Michaels, G. (2015). Robots at Work. Discussion Paper No. 1335, CEP.

Manyika, J., \& Sneader, K. (2018, June 1). AI, Automation, and the Future of Work: Ten Things to Solve for. McKinsey Global Institute.

https://www.mckinsey.com/featured-insights/future-of-work/ai-automation-and-the-f uture-of-work-ten-things-to-solve-for\#

Mckinsey Global Institute (2017, December 6). Jobs Lost, Jobs Gained: Workforce Tran- 
sitions in a Time of Automation.

https://www.mckinsey.com/ /media/McKinsey/Industries/Public\%20and\%20Social\%2 0Sector/Our\%20Insights/What\%20the\%20future\%20of\%20work\%20will\%20mean\%20f or\%20jobs\%20skills\%20and\%20wages/MGI-Jobs-Lost-Jobs-Gained-Report-December6-2017.pdf

World Economic Forum (2018). The Future of Jobs Report 2018. World Economic Forum. http://www3.weforum.org/docs/WEF Future of Jobs 2018.pdf

Zeira, J. (1998). Workers, Machines, and Economic Growth. Quarterly Journal of Economics, 113, 1091-1117. https://doi.org/10.1162/003355398555847

Zinser, M., Sirkin, H., \& Rose, J. R. (2015, September 23). The Robotics Revolution: The Next Great Leap in Manufacturing. Boston Consulting Group.

https://www.bcg.com/publications/2015/lean-manufacturing-innovation-robotics-revo lution-next-great-leap-manufacturing 